\title{
Effects of orally applied butyrate bolus on histone acetylation and cytochrome P450 enzyme activity in the liver of chicken - a randomized controlled trial
}

Gábor Mátis ${ }^{1}$, Zsuzsanna Neogrády ${ }^{1}$, György Csikó², Anna Kulcsár ${ }^{1}$ Ákos Kenéz ${ }^{3}$ and Korinna Huber ${ }^{3 *}$

\begin{abstract}
Background: Butyrate is known as histone deacetylase inhibitor, inducing histone hyperacetylation in vitro and playing a predominant role in the epigenetic regulation of gene expression and cell function. We hypothesized that butyrate, endogenously produced by intestinal microbial fermentation or applied as a nutritional supplement, might cause similar in vivo modifications in the chromatin structure of the hepatocytes, influencing the expression of certain genes and therefore modifying the activity of hepatic microsomal drug-metabolizing cytochrome P450 (CYP) enzymes.

Methods: An animal study was carried out in chicken as a model to investigate the molecular mechanisms of butyrate's epigenetic actions in the liver. Broiler chicks in the early post-hatch period were treated once daily with orally administered bolus of butyrate following overnight starvation with two different doses $(0.25$ or $1.25 \mathrm{~g} / \mathrm{kg}$ body weight per day) for five days. After slaughtering, cell nucleus and microsomal fractions were separated by differential centrifugation from the livers. Histones were isolated from cell nuclei and acetylation of hepatic core histones was screened by western blotting. The activity of CYP2H and CYP3A37, enzymes involved in biotransformation in chicken, was detected by aminopyrine $\mathrm{N}$-demethylation and aniline-hydroxylation assays from the microsomal suspensions.
\end{abstract}

Results: Orally added butyrate, applied in bolus, had a remarkable impact on nucleosome structure of hepatocytes: independently of the dose, butyrate caused hyperacetylation of histone $\mathrm{H} 2 \mathrm{~A}$, but no changes were monitored in the acetylation state of $\mathrm{H} 2 \mathrm{~B}$. Intensive hyperacetylation of $\mathrm{H} 3$ was induced by the higher administered dose, while the lower dose tended to increase acetylation ratio of $\mathrm{H} 4$. In spite of the observed modification in histone acetylation, no significant changes were observed in the hepatic microsomal CYP2H and CYP3A37 activity.

Conclusion: Orally added butyrate in bolus could cause in vivo hyperacetylation of the hepatic core histones, providing modifications in the epigenetic regulation of cell function. However, these changes did not result in alteration of drug-metabolizing hepatic CYP2H and CYP3A37 enzymes, so there might be no relevant pharmacoepigenetic influences of oral application of butyrate under physiological conditions.

Keywords: Short chain fatty acids, Butyrate, Histone deacetylase inhibitor, Histone hyperacetylation, Epigenetics, Cytochrome P450 enzymes

\footnotetext{
* Correspondence: Korinna.Huber@tiho-hannover.de

${ }^{3}$ Department of Physiology, University of Veterinary Medicine, Bischofsholer Damm 15/102, D-30173, Hannover, Germany

Full list of author information is available at the end of the article
} 


\section{Background}

Short chain fatty acids (SCFA) are produced physiologically by the anaerobic microbial fermentation of dietary compounds in the rumen of polygastric animals and mostly fibers in the large intestine of monogastric mammals, birds and humans [1]. Butyrate is of special interest due to its numerous positive effects on the health of gut and extraintestinal tissues. Butyrate is the most important energy source of the colonocytes [2], regulating also the proliferation and differentiation of the gastrointestinal epithelium [3] and inducing apoptosis in genetically disordered cells $[4,5]$. As a consequence, butyrate has a protective effect against colorectal cancer, which was reported in some in vitro [6] and also in vivo animal studies $[7,8]$. Due to its selective antimicrobial action on most enteral pathogens $[9,10]$, butyrate improves the balance of the intestinal microflora, which can influence the health of the host animal or the human host [11].

Fiber-rich diet or uptake of resistant starch increases microbial butyrate production, but butyrate is also orally applicable in several forms. In animal nutrition, due to its numerous beneficial properties improving health and also the growth performance of pigs [12] and chickens [13], butyrate is of special interest as a nutritional supplement, especially after the banning of the traditional antibiotical growth promoters in the European Union [14].

Furthermore, as an epigenetic factor, butyrate regulates the transcription via influencing core histone acetylation, which is one of the most relevant epigenetic regulations of the cell function together with DNA methylation [15]. The dynamic balance of acetylation of histone proteins at certain lysine residues is regulated by the opposing effects of histone acetyltransferases (HAT) and histone deacetylases (HDAC) [15]. Butyrate inhibits Class I and most of the Class II HDAC enzymes, causing histone hyperacetylation at lysine residues of the N-terminal tail, therefore modifying the expression of certain genes [16]. In addition to the several in vitro studies [17], increased total histone acetylation was reported in case of porcine caecal tissue after dietary supplementation with the butyrate precursor lactulose [18]. Butyrate-induced histone modifications may be highly involved in butyrate's antitumor, antibacterial and metabolic effects [19].

Although butyrate is greatly metabolized by the intestinal epithelium, a certain amount is also absorbed into the portal blood [20] and taken up by the liver in rat and human in vivo $[21,22]$. Butyrate is an important energy source for the liver as a substrate of the oxidative pathways, but it is also a potent effector of the hepatic metabolism. It can decrease the mitochondrial oxidative phosphorylation yield and the ATP content of the liver due to its uncoupling-like effect $[23,24]$ and can influence the mitochondrial ATP turnover linked to glycogen metabolism [25].
It is known that the expression of certain microsomal cytochrome P450 (CYP) monooxygenases, playing a predominant role in biotransformation, drug and steroid metabolism, can be affected by histone modifications [26]. For instance, the HDAC inhibitor trichostatin A was shown to influence the in vitro expression of the CYP3A subfamily [27]. Alimentary added inulin, which is fermented by the colonic bacteria to SCFA, alleviates the reduction in the expression and activity of hepatic CYP1A1/2 and CYP2E1 enzymes in rats kept on a highfat diet [28], possibly due to the epigenetic effects of the absorbed SCFA. On the basis of these findings, the enteral microbiome-produced or the orally added butyrate may also alter the activity of CYP enzymes, have an impact on hepatic detoxification capacity and drug metabolism, defined as possible pharmacoepigenetic influences.

The present study aimed to evaluate the epigenetic effects of butyrate added orally to broiler chickens in a daily bolus. These animals have a large capacity of growing and intensive hepatic metabolism. Young chickens have quite low rates of butyrate production in the large intestine [29], so they can be proper candidates in order to study the effects of the orally applied butyrate. Unlike in our previous study with butyrate evenly mixed in the feedstuff of the chicken, butyrate administered in bolus after starvation provides a fast, but short-term release of greater amount of butyrate to the portal vein and an intensive stimulus for the liver. The lower dose of butyrate, $0.25 \mathrm{~g} / \mathrm{kg}$ body weight (BW) was chosen regarding the usual applied concentration of butyrate as a nutritional supplement. With the higher administered concentration, $1.25 \mathrm{~g} / \mathrm{kg} \mathrm{BW}$ we aimed to provide high amount of butyrate for the hepatocytes to study also the dose-dependency of its action.

After butyrate treatments, at first we wanted to monitor the modifications in the acetylation state of hepatic core histones at the most frequent acetylation sites. Our second goal was to measure the activity of $\mathrm{CYP} 2 \mathrm{H}$ and CYP3A37 enzymes to screen, whether butyrate in bolus can influence the detoxification capacity of the liver.

\section{Methods \\ Chemicals}

Chemicals were purchased from Sigma-Aldrich (Munich, Germany) except when otherwise specified.

\section{Animals}

One-day-old broiler chicks of the Ross 308 strain (mixed gender) were obtained from a commercial hatchery (Bábolna Tetra Company, Uraiújfalu, Hungary). Animals were housed individually in metal pens in a room with controlled environment conditions of Ross technology [30]. Feed and water were provided ad libitum. The diet was formulated according to the requirements of the 
starter period and was free from any medication or chemical additives. Composition of the diet is shown in Table 1.

All procedures were conducted in accordance with international and national laws and institutional guidelines and approved by the Local Animal Test Committee of the Faculty of Veterinary Science, Szent István University, Budapest, Hungary (number of permission: 22.1/4719/ 003/2008).

\section{Treatments}

On days 20-24 experimental animals were fasted overnight for $12 \mathrm{~h}$ and thereafter treated once daily by a crop-tube with an intraingluvial bolus according to the following protocol: (i) ten chickens received $0.1 \mathrm{~g} / \mathrm{ml}$ sodium butyrate solution $(2.5 \mathrm{ml} / \mathrm{kg} \mathrm{BW}$, which equals $0.25 \mathrm{~g}$ sodium butyrate $/ \mathrm{kg}$ BW daily, $1.25 \mathrm{~g}$ sodium butyrate $/ \mathrm{kg}$ BW for the total treatment period, which is approx. $0.95 \mathrm{~g} / \mathrm{animal}$ in average); (ii) ten broilers were treated with $0.5 \mathrm{~g} / \mathrm{ml}$ sodium butyrate solution $(2.5 \mathrm{ml} / \mathrm{kg} \mathrm{BW}$, which equals $1.25 \mathrm{~g}$ sodium butyrate/kg BW daily, 6.25 g sodium butyrate/kg $\mathrm{BW}$ for the total treatment period, which is approx. $4.75 \mathrm{~g} /$ animal in average); (iii) distilled water $(2.5 \mathrm{ml} / \mathrm{kg} \mathrm{BW})$ was applied for ten chicks as a control group. The butyrate boli

Table 1 Composition of the diet of chickens

\begin{tabular}{lc}
\hline Item & \\
\hline Ingredient, g/kg & \\
Corn & 593.7 \\
Soybean meal & 310.0 \\
Corn gluten meal & 50.0 \\
Limestone & 15.0 \\
Monocalcium phosphate & 18.5 \\
NaCl & 4.0 \\
Vitamin-mineral mixture 1 & 6.0 \\
L-Lysine HCl & 1.8 \\
DL-Methionine & 1.0 \\
Calculated nutrient composition & \\
Crude protein, g/kg & \\
Ether extract, g/kg & 212.2 \\
Crude fiber, g/kg & 29.4 \\
Ash, g/kg & 25.3 \\
AME, MJ/kg & 65.9 \\
Lysine, g/kg & 11.6 \\
Methionine, g/kg & 11.9 \\
Methionine + Cysteine, g/kg & 11.9 \\
Calcium, g/kg & 4.9 \\
\hline & \\
Available phosphorus, g/kg & 25.9 \\
\hline
\end{tabular}

${ }^{1}$ Provided (per kilogram of diet): Se, 0.24 mg; Fe, 135 mg; Mn, 136 mg; Cu, $22 \mathrm{mg}$; Zn, $110 \mathrm{mg}$; l, $1.2 \mathrm{mg}$; retinyl acetate, $4.14 \mathrm{mg}$; cholecalciferol $0.075 \mathrm{mg}$; a-tocopherol, $26.85 \mathrm{mg}$, choline chloride, $360 \mathrm{mg}$; menadione, $3.0 \mathrm{mg}$; riboflavin, $7.0 \mathrm{mg}$; cobalamine, $0.03 \mathrm{mg}$; niacin, $40 \mathrm{mg}$; pantothenic acid, $12 \mathrm{mg}$; folic acid, $1.0 \mathrm{mg}$; pyridoxine, $5.0 \mathrm{mg}$. did not cause any macroscopic pathomorphological alterations in the mucosa of the gastrointestinal tract, which may have been caused by higher osmolarity of the applied solutions. In addition, (iv) six broilers were treated on days 20-24 by intracoelomal phenobarbital (PB) injection (Phenobarbital sodium, Ph. Eur. 7.1, dissolved in sterile, pyrogen-free and endotoxin-free physiological saline solution, applied dose: $80 \mathrm{mg} / \mathrm{kg} \mathrm{BW}$ daily) to induce CYP activity as a positive control. Body weight was measured individually on each day of treatment, boli and PB injections were adjusted to the measured body weight per day. (Mean body weight of the animals was $0.683 \pm 0.011 \mathrm{~kg}$ on day 20 and $0.774 \pm 0.017 \mathrm{~kg}$ on day 24.) All animals were starved for additional $2 \mathrm{~h}$ after each treatment in order to enhance the absorption of butyrate. Daily body weight gain and feed intake matched the requirements of the Ross technology and no significant difference could be observed between the groups. However, the applied butyrate provided some extra energy for the treated animals (calculated mean metabolizable energy content of the boli was $2.8 \mathrm{~kJ} /$ animal daily at the lower and $13.9 \mathrm{~kJ} /$ animal daily at the higher dose), it appeared not to be relevant compared to the energy content of the diet (calculated mean metabolizable energy provided by the diet taken up was $1190 \mathrm{~kJ} /$ animal daily).

\section{Liver sampling and separation of subcellular organelles}

Animals were slaughtered in carbon dioxide anaesthesia by decapitation on day 24 . Last treatment was conducted $2 \mathrm{~h}$ prior to slaughtering. After opening the coelom, the liver was exsanguinated with chilled physiological saline solution through the portal vein and was ectomized, weighed and shock-frozen immediately in liquid nitrogen.

After thawing, cell nucleus fraction was isolated from the liver of the bolus-treated and control chickens (treatments i, ii, iii) in order to examine the acetylation state of the core histones, while microsomal fractions were prepared from all animals (treatments i, ii, iii, iv) to study the hepatic CYP activity.

Subcellular organelles were isolated by differential centrifugation according to the protocol of Van der Hoeven [31]. Microsomal total protein concentration was determined with a Bicinchoninic Acid Protein Assay Kit (Fisher Scientific, Rockford, IL, USA) on a microplate in triplicates, using bovine serum albumin (BSA) as a standard.

All cell nucleus and microsomal fractions were shockfrozen in liquid nitrogen and were stored at $-80^{\circ} \mathrm{C}$ until further examinations.

\section{Histone isolation}

Purified histone extracts were isolated by a Histone Purification Mini Kit (Active Motif, Carlsbad, CA, USA) from cell nucleus fractions according to the manufacturer's 
protocol. During the whole purification procedure kit reagents prevented further deacetylase activity to ensure acetylation status as in vivo.

Equal volume of ice-cold Extraction Buffer was added to the nucleus suspension. After homogenization, samples were incubated overnight at $4^{\circ} \mathrm{C}$ on a rotating platform. Tubes were centrifuged at maximum speed $(30,000 \mathrm{~g})$ for $5 \mathrm{~min}$ in a microfuge, and the supernatant, considered as the crude histone extract, was neutralized with one-fourth volume of $5 x$ Neutralization Buffer ( $\mathrm{pH}$ 8.0). Neutralized extract was loaded onto previously equilibrated histone isolation spin columns. After 3 washing steps with Wash Buffer, histones were eluted and precipitated overnight from the flow-through by $4 \%$ perchloric acid. Precipitate was sedimented by centrifugation at $30,000 \mathrm{~g}$ for $60 \mathrm{~min}$, the pellet was washed at first with $4 \%$ perchloric acid, later with acetone, containing $0.2 \% \mathrm{HCl}$ and finally with pure acetone. Histones were resuspended in sterile distilled water and the yield of total core histone proteins was quantified by measuring the absorbance at $230 \mathrm{~nm}$.

\section{Western blot analysis}

Electrophoresis and western blotting were performed according to the instructions of the applied Acetyl Histone Antibody Sampler Kit (Cell Signaling, MA, USA). Histone preparations were diluted by SDS- and mercaptoethanolcontaining loading buffer (supplemented with $50 \mathrm{mM}$ dithiothreitol), sonicated for $15 \mathrm{sec}$ in order to reduce viscosity and proteins were heat denatured at $95^{\circ} \mathrm{C}$ for $5 \mathrm{~min}$. Histones were separated by SDS-PAGE on polyacrylamide (4-20\%) precast gradient gels (Biorad Laboratories, CA, USA), the amount of loaded protein was $3 \mu \mathrm{g}$ per lane for the detection of histones $\mathrm{H} 2 \mathrm{~A}$ and $\mathrm{H} 3$, while $6 \mu \mathrm{g}$ per lane for histones $\mathrm{H} 2 \mathrm{~B}$ and $\mathrm{H} 4$. After tank blotting of proteins onto nitrocellulose membranes $(0.2 \mu \mathrm{m}$ pore size, Biorad Laboratories, CA, USA), histones were identified by immunodetection using antibodies of the Acetyl Histone Antibody Sampler Kit: after blocking with 5\% fat-free milk-containing PBST for $2 \mathrm{~h}$, the immunoblots were incubated overnight with primary antibodies against histone H2A (1:1000), H2B (1:500), H3 (1:1000), H4 (1:500) and their acetylated forms. Each acetyl histone antibody was specific for the target histone modified at the lysine residue of the most frequent acetylation site $(\mathrm{H} 2 \mathrm{~A}$ and H2B: Lys 5, H3: Lys 9, H4: Lys 8). Detection of the primary antibody was performed using an anti-rabbit secondary antibody (1:2000) coupled with horseradish peroxidase. Primary antibodies were diluted in PBST, containing 5\% BSA, while secondary antibodies in PBST, containing 5\% fat-free milk. Bands were detected by the Chemidoc XRS enhanced chemiluminescence system (Biorad Laboratories, CA, USA). Membranes were finally stained by Indian Ink to detect all the separated proteins. Band intensities were quantified by the Quantity One 1-D
Analysis software (Biorad Laboratories, CA, USA), trace quantities were standardized to the Indian Ink stained bands to ensure equal loading. Acetylation ratios were determined considering relative protein expression levels of each histone and its acetylated form.

All western blot examinations were carried out in duplicates. Regarding histone H3, due to their different molecular mass, trace quantities of bands representing H3.1 and H3.2 isoforms could be measured separately, but the acetylation state was calculated from the total amount of $\mathrm{H} 3$ and acetyl-H3.

\section{Enzyme assays on hepatic microsomal CYP activity Aminopyrine $\mathrm{N}$-demethylation assay}

Microsomal CYP2H/CYP3A37 activity was screened by the aminopyrine $\mathrm{N}$-demethylation assay, in which formaldehyde production could be measured by the spectrophotometric method of Nash [32]. The enzyme assay was performed according to the modified protocol of García-Agúndez et al. [33]. The reaction mixture contained an $\mathrm{NADPH}+\mathrm{H}^{+}$-regenerating cofactor mixture, prepared from $0.5 \mathrm{mM} \mathrm{NADPH}+\mathrm{H}^{+}$(Reanal Private Ltd., Budapest, Hungary), $50 \mathrm{mM}$ glucose 6-phosphate, $4 \mathrm{IU} / \mathrm{l}$ glucose 6-phosphate dehydrogenase, $5 \mathrm{mM} \mathrm{MgCl}_{2}$ and $50 \mathrm{mM}$ semicarbazide.

After thawing on ice, $100 \mu \mathrm{l}$ microsomal suspension was incubated with $200 \mu \mathrm{l}$ cofactor mixture and $900 \mu \mathrm{l}$ $0.05 \mathrm{M}$ phosphate buffer ( $\mathrm{pH}$ 7.4) in the presence of different concentrations $(0,1.25,2.5,5,10 \mathrm{mM})$ of dimethylamino-antipyrine (aminopyrine) for $10 \mathrm{~min}$ at $37^{\circ} \mathrm{C}$. The reaction was stopped by adding $200 \mu \mathrm{l} 20 \%$ trichloroacetic acid. After centrifugation at 4,500 $\mathrm{g}$ for $10 \mathrm{~min}, 400 \mu \mathrm{l}$ Nash reagent $(0.16 \mathrm{ml}$ acetyl acetone and $0.24 \mathrm{ml}$ concentrated acetic acid in $20 \mathrm{ml}$ of $4 \mathrm{M}$ ammonium acetate solution) was added to $800 \mu \mathrm{l}$ of the supernatant. The mixture was incubated at $60^{\circ} \mathrm{C}$ for $30 \mathrm{~min}$, cooled down on ice and the absorbance was measured spectrophotometrically at $415 \mathrm{~nm}$ against reagent blank. Results were corrected by subtracting the absorbance of an inhibited blank per each substrate concentration (inhibited previously by adding $20 \%$ trichloroacetic acid). Formaldehyde standard curves were determined under the same conditions as used for microsomal activity measurements; each sample was examined in triplicates. Finally, mean specific enzyme activity (reaction velocity), maximal reaction velocity $\left(\mathrm{V}_{\max }\right)$ and the Michaelis-Menten's constant $\left(\mathrm{K}_{\mathrm{M}}\right)$ were calculated and compared between groups. All results were standardized according to the total protein concentration of microsomal samples.

\section{Aniline-hydroxylation assay}

$\mathrm{CYP} 2 \mathrm{H}$ activity was measured by aniline-hydroxylation assay. The enzyme assay was carried out according to the modified protocol of Murray and Ryan [34]. The reaction 
mixture contained an $\mathrm{NADPH}+\mathrm{H}^{+}$-regenerating cofactor mixture with the same composition as for the aminopyrine N-demethylation assay. After thawing on ice, $100 \mu \mathrm{l}$ microsomal suspension was incubated with $200 \mu \mathrm{l}$ cofactor mixture and $900 \mu \mathrm{l} 0.05 \mathrm{M}$ phosphate buffer ( $\mathrm{pH} 7.4$ ) and different concentrations $(0,1.25,2.5,5,10 \mathrm{mM})$ of aniline hydrochloride for $15 \mathrm{~min}$ at 37 . The reaction was terminated by adding $200 \mu \mathrm{l} 20 \%$ trichloroacetic acid. Following centrifugation at 4,500 g for $10 \mathrm{~min}, 400 \mu \mathrm{l} \mathrm{10 \%}$ $\mathrm{Na}_{2} \mathrm{CO}_{3}$ solution and $400 \mu \mathrm{l}$ alkaline phenol solution ( $0.8 \%$ phenol solution in $0.2 \mathrm{M} \mathrm{NaOH}$ ) were added to $400 \mu \mathrm{l}$ of the supernatant. The mixture was incubated at $37^{\circ} \mathrm{C}$ for $30 \mathrm{~min}$, cooled down on ice and the absorbance was measured by spectrophotometer at $605 \mathrm{~nm}$ against reagent blank. An inhibited blank was approved for each substrate concentration similarly to the aminopyrine $\mathrm{N}$-demethylation assay. To determine the amount of the produced 4-aminophenol, standard curves were prepared; each sample was examined in triplicates. Mean specific enzyme activity, $V_{\max }$ and $K_{M}$ values were also determined and compared between groups. All results were standardized according to the total protein concentration of microsomal samples.

\section{Statistics}

All values are expressed as means \pm SEM. Statistical analysis of data was performed with $\mathrm{R} 2.14 .0$ software (downloaded from http://cran.r-project.org/bin/windows/base/old/2.14.0/ on 14 December 2011), one-tailed non-parametric Mann-Whitney's test and one-way ANOVA were approved for comparison of results of the treated groups with those of controls. Level of significance was set at $\mathrm{P}<0.05$.

\section{Results and discussion}

\section{Acetylation of hepatic core histones}

Screening of the important acetylation sites of core histones showed that butyrate treatment in bolus at the lower dose $(0.25 \mathrm{~g} / \mathrm{kg} \mathrm{BW})$ tended to increase acetylation of histone $\mathrm{H} 2 \mathrm{~A}$ at lysine $5(\mathrm{P}=0.063)$, and the higher applied dose $(1.25 \mathrm{~g} / \mathrm{kg} \mathrm{BW})$ caused significant, approximately twofold increase in acetylation $(\mathrm{P}=0.048)$ compared to the control group at the same acetylation site of H2A (Figure 1A and Figure 2).

Confirming this finding, butyrate induced hyperacetylation of $\mathrm{H} 2 \mathrm{~A}$ in colonic epithelial cell culture in vitro [35]. Acetylation of $\mathrm{H} 2 \mathrm{~A}$ is of special importance since its acetylation state is highly involved in conformational changes of the nucleosome and decreased histone-DNA interactions, working synergistically with acetylation of the N-terminal histone tails [36,37].

In contrast, butyrate bolus did not influence the acetylation of histone $\mathrm{H} 2 \mathrm{~B}$ at lysine 5 with the lower $(\mathrm{P}=0.274)$ nor the higher dose of butyrate $(\mathrm{P}=0.714)$
(Figure 1B and Figure 2). There are still some other lysine residues in $\mathrm{H} 2 \mathrm{~B}$, which may be potential targets of HDAC inhibitors [38], and possible effects of butyrate on these other acetylation sites cannot be excluded.

There was no significant difference in the acetylation ratio of total histone $\mathrm{H} 3$ at lysine 9 after the application of butyrate in the lower dose $(\mathrm{P}=0.146)$. However, higher dose of butyrate caused relevant, approximately 18 -fold increased $\mathrm{H} 3$ acetylation ratio $(\mathrm{P}=0.009)$ (Figure $1 \mathrm{C}$ and Figure 2). Hyperacetylation of $\mathrm{H} 3$ after butyrate exposure was reported by several in vitro studies in a variety of cultured mammalian cells, but not yet described in vivo. It was found already in 1973 that butyrate in millimolar concentrations caused hyperacetylation of $\mathrm{H} 3$ and $\mathrm{H} 4$ in all examined vertebrate cell lines, while $\mathrm{H} 2 \mathrm{~A}$ and $\mathrm{H} 2 \mathrm{~B}$ were also affected in certain rat-derived cell cultures [17]. Butyrate-induced dynamic histone acetylation was compared between mammalian and avian cells in vitro [16], where huge amount of highly acetylated H3 isoforms was found after butyrate treatment in human breast cancer cells, in contrast of terminally differentiated avian immature erythrocytes, $2 \%$ of which participated in the acetylation process. Among the many acetylation sites, in agreement with our results, it was recently described that butyrate induced $\mathrm{H} 3$ hyperacetylation first of all at lysine 9, an acetylation site that plays a critical role in the epigenetic regulation of cell function [39]. Since this acetylation site is linked to histone phosphorylation and methylation processes, these site-specific modifications together can cause distinct chromatin alterations and cell cycle modifications [40].

The H3 isoforms H3.1 and H3.2 could be also separated on the immunoblots and it was found that butyrate increased the relative protein expression level of the H3.1 isoform, which was poorly expressed in control animals, but was detected in high amount in both butyrate-treated groups. The difference in the relative protein expression level of H3.1 between the control and butyrate-treated groups was considered to be significant after the application of the lower dose $(\mathrm{P}=0.021)$ and a near-significant trend following treatment with the higher dose $(\mathrm{P}=0.090)$ of butyrate. It is known that three $\mathrm{H} 3$ variants (H3.1, H3.2, H3.3) do exist in mammals, specifically, H3.1 is involved in both chromatin activation and repression, while H3.2 plays an important role in gene repression and H3.3 is especially enriched in active marks [41]. Unlike in the case of mammals, only H3.1 and H3.2 could be separated from chicken cells [42]. Due to the pleiotropic effect of H3.1 on transcription, increased protein expression level of H3.1 after butyrate treatment, detected in our present study, may be also of special importance.

Regarding the acetylation of histone $\mathrm{H} 4$ at lysine 8 , butyrate tended to induce hyperacetylation at the lower administered dose $(\mathrm{P}=0.063)$ (Figure $1 \mathrm{D}$ and Figure 2). 


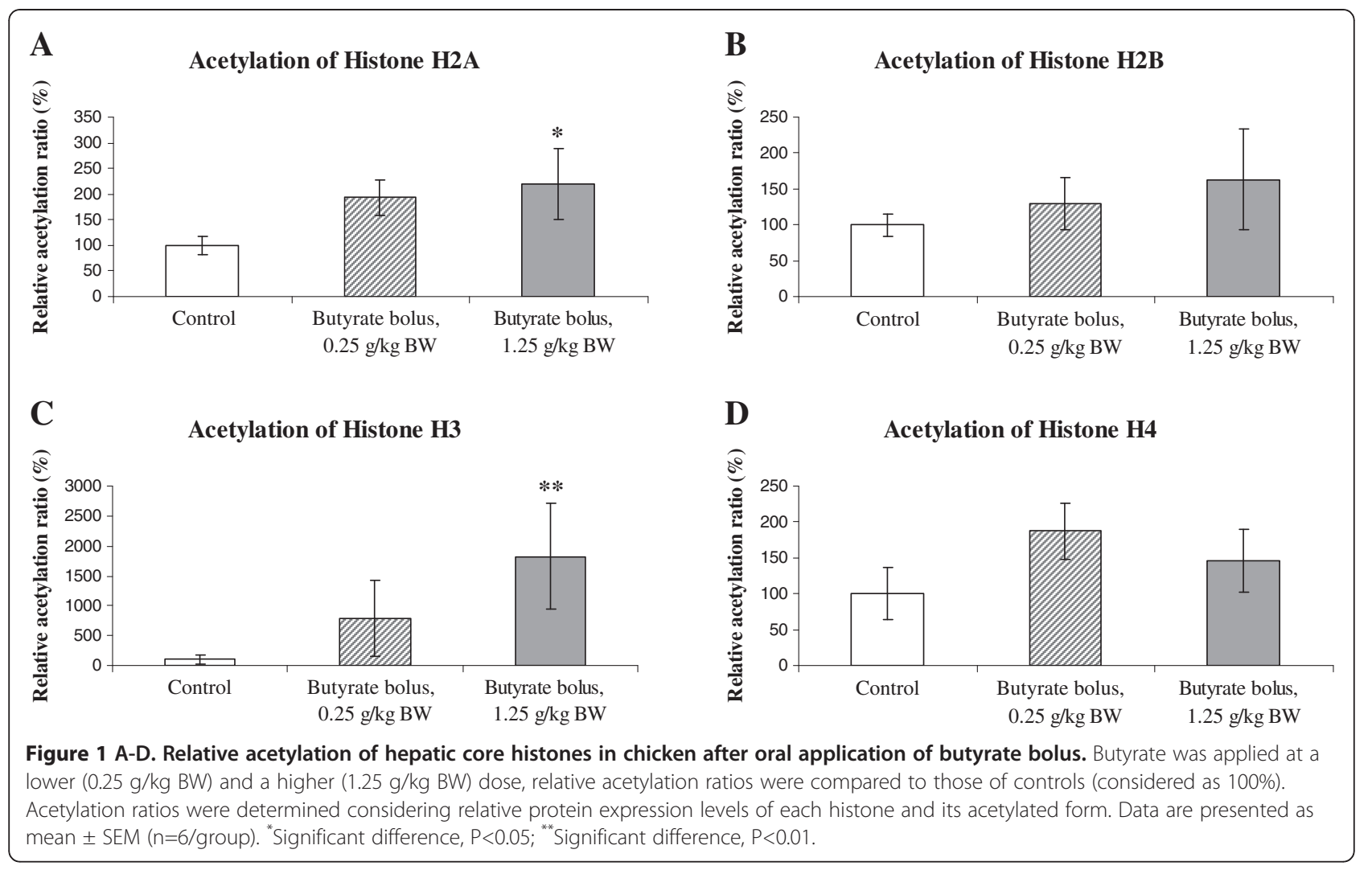

Similarly to H3, H4 is also a highly involved target of butyrate-induced hyperacetylation in cell cultures [17]. It is known that acetylation and deacetylation of $\mathrm{H} 4$ is a well-coordinated process, and butyrate-induced tetraand tri-acetylated forms of $\mathrm{H} 4$ are always acetylated at lysine 8 [38]. Therefore, the lysine residue examined in this study is considered as one of the most important acetylation sites of $\mathrm{H} 4$. It was recently also stated that $\mathrm{H} 3$ at lysine 9 and $\mathrm{H} 4$ at lysine 8 are critical targets of butyrate-induced histone hyperacetylation, which process is associated with the G-protein-coupled receptor-41, also activated by butyrate [43]. Interestingly, the acetylation ratio of $\mathrm{H} 4$ after force-feeding with the higher dose of butyrate was not increased significantly compared to the control group $(\mathrm{P}=0.210)$ (Figure 1D and Figure 2). Butyrate can also alter the activity of HAT enzymes, and this contradictory finding may be in association with the pleiotropic effects of butyrate on HAT and HDAC [44], depending also on the dose of butyrate.

Very little data can be found in literature regarding the in vivo effects of butyrate on the chromatin structure. In a recent study, significant increase in total histone acetylation was reported in the caecal tissue of pigs after receiving orally administered lactulose, which was intensively fermented to butyrate in the large bowel [18].

It is also interesting to compare the present results after butyrate application in bolus with our recent ex- periment [45], where butyrate was applied as a nutritional supplement for broiler chickens for three weeks at the concentration of $1.5 \mathrm{~g} / \mathrm{kg}$ diet. Dosage of butyrate as a supplement was approximately equivalent with the lower dose bolus $(0.25 \mathrm{~g} / \mathrm{kg} \mathrm{BW})$ in the present study. The most important difference between the treatments is that the administration of butyrate in bolus after overnight starvation provides a short-term supply of greater amount of butyrate for the hepatocytes. In the earlier experiment animals could take up butyrate-supplemented diet the whole day, but this uptake might be followed by a prolonged absorption and a long-acting butyrate exposure of the liver.

In both experiments, hyperacetylation of $\mathrm{H} 2 \mathrm{~A}$ at lysine 5 was found and no dose-dependency could be detected after bolus treatment. In spite of these results, it can be stated that butyrate did not affect the acetylation state of histone $\mathrm{H} 2 \mathrm{~B}$ at lysine 5 after butyrate administration in bolus, nor in the nutritional supplement study. Similarly to our earlier experiment, where butyrate was applied as a nutritional supplement, the lower dose of butyrate bolus did not cause any changes in the acetylation of histone $\mathrm{H} 3$ at lysine, but the higher dose induced a highly relevant hyperacetylation of $\mathrm{H3}$ at lysine 9. Due to the key-role of $\mathrm{H} 3$ modifications in gene expression $[39,40]$, this action seems to be a very important change in the epigenetic regulation of transcription. Lower dose 


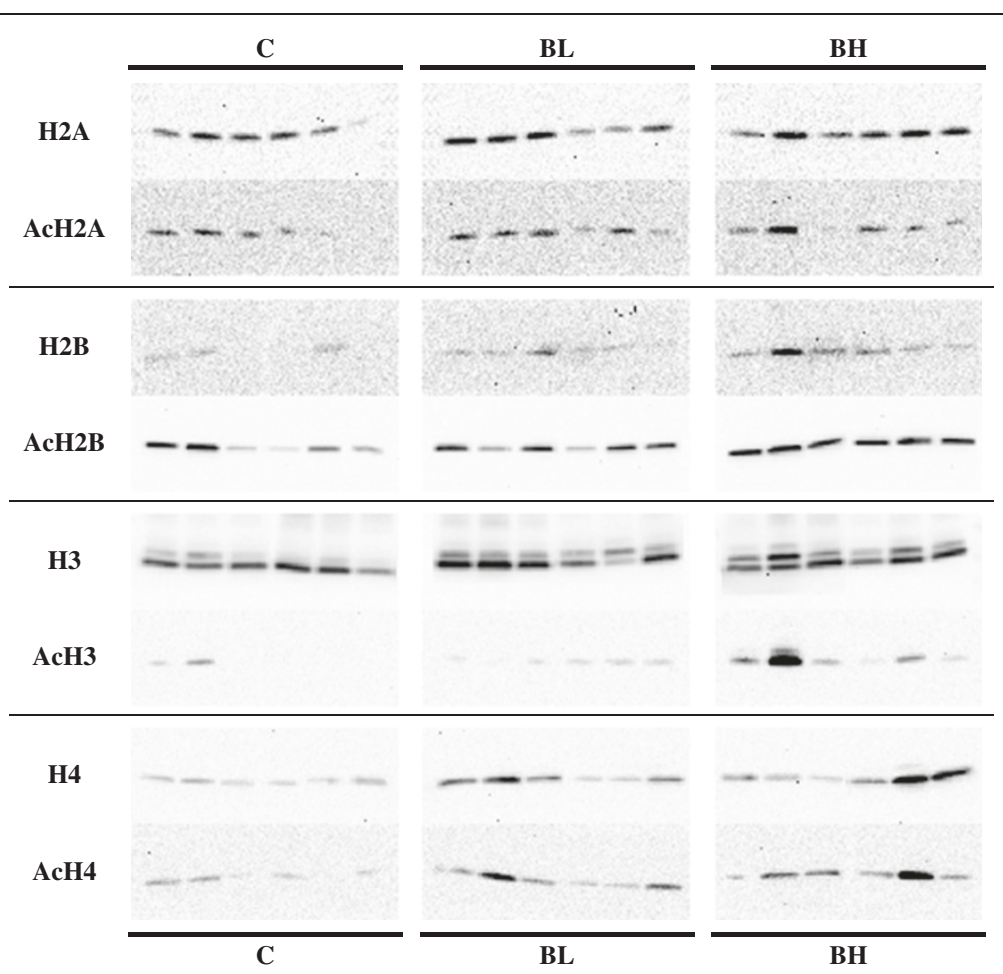

Figure 2 Representative bands as obtained by western blotting from isolated hepatocyte histones of chickens. Columns show the bands of control animals (C) and chicks after oral application of butyrate bolus at the dose of $0.25 \mathrm{~g} / \mathrm{kg}$ body weight (BL) and the dose of $1.25 \mathrm{~g} / \mathrm{kg}$ body weight (BH). The upper rows show the relative protein expression levels of total $\mathrm{H} 2 \mathrm{~A}, \mathrm{H} 2 \mathrm{~B}, \mathrm{H} 3$ and $\mathrm{H} 4$, respectively, while the bands specific for acetylated histones of the same animals can be seen below (AcH1-4). At histone H3, the upper band can be identified as the H3.1 isoform and the lower as H3.2. Western blots were done in duplicates for all histones.

of butyrate tended to increase acetylation of $\mathrm{H} 4$ at lysine 8 , differing from the nutritional supplement experiment, underlining the critical role of the application.

We can summarize that orally applied butyrate in bolus influenced hepatic histone acetylation in vivo, core histones $\mathrm{H} 2 \mathrm{~A}, \mathrm{H} 3$ and $\mathrm{H} 4$ were involved in this partly dosedependent action. Since butyrate modified the chromatin structure, it can be considered as an important epigenetic effector on gene expression of hepatocytes. Therefore, hepatic CYP activity was measured as key surrogate to assess changes in gene expression and subsequently, function.

\section{Activity of hepatic microsomal CYP enzymes}

We hypothesized that butyrate-induced histone modifications might cause changes in hepatic CYP activity; because it was reported that histone acetylation had a huge impact on gene expression of several members of the CYP2 family [26]. It is also known that alterations in histone $\mathrm{H} 3$ acetylation are involved in the expression of CYP3A subfamily in the adult mouse [46]. However, in our experiment, butyrate-induced epigenetic changes of chromatin structure did not result in changes of enzyme activity.
Screening the aminopyrine $\mathrm{N}$-demethylation activity of hepatic microsomal fractions, catalyzed by $\mathrm{CYP} 2 \mathrm{H}$ and CYP3A37 enzymes, no significant difference was found between the mean enzyme activity (reaction velocity) of the butyrate-treated animals and those of controls (lower dose: $\mathrm{P}=0.196$, higher dose: $\mathrm{P}=0.523$ ) (Figure $3 \mathrm{~A}$ ). Similarly, administration of butyrate bolus caused no significant differences in the $\mathrm{V}_{\max }$ values, independently of the applied dose (lower dose: $\mathrm{P}=0.368$, higher dose: $\mathrm{P}=0.911$ ). The lower concentration of butyrate did not affect the $K_{M}$ value $(\mathrm{P}=0.713)$, but the higher dose tended to decrease it $(\mathrm{P}=0.095)$, however, due to high standard error of mean it can be considered only as a near-significant trend (Table 2).

As an enzyme inductor, PB treatment caused notable enzyme induction with significantly increased mean reaction velocity $(\mathrm{P}=0.003)$ (Figure $3 \mathrm{~A})$ and $\mathrm{V}_{\max }$ values $(\mathrm{P}=0.009)$, but did not influence the $\mathrm{K}_{\mathrm{M}}(\mathrm{P}=0.878)$ of the reaction (Table 2).

In agreement with these results, butyrate treatment in bolus did not alter the aniline-hydroxylation activity of the liver, specific for the microsomal CYP2H subfamily. No significant difference was found in the mean enzyme activity (lower dose: $\mathrm{P}=0.211$, higher dose: $\mathrm{P}=0.848$ ) (Figure $3 \mathrm{~B}$ ), $\mathrm{V}_{\max }$ (lower dose: $\mathrm{P}=0.700$, higher dose: $\mathrm{P}=0.640$ ) and 


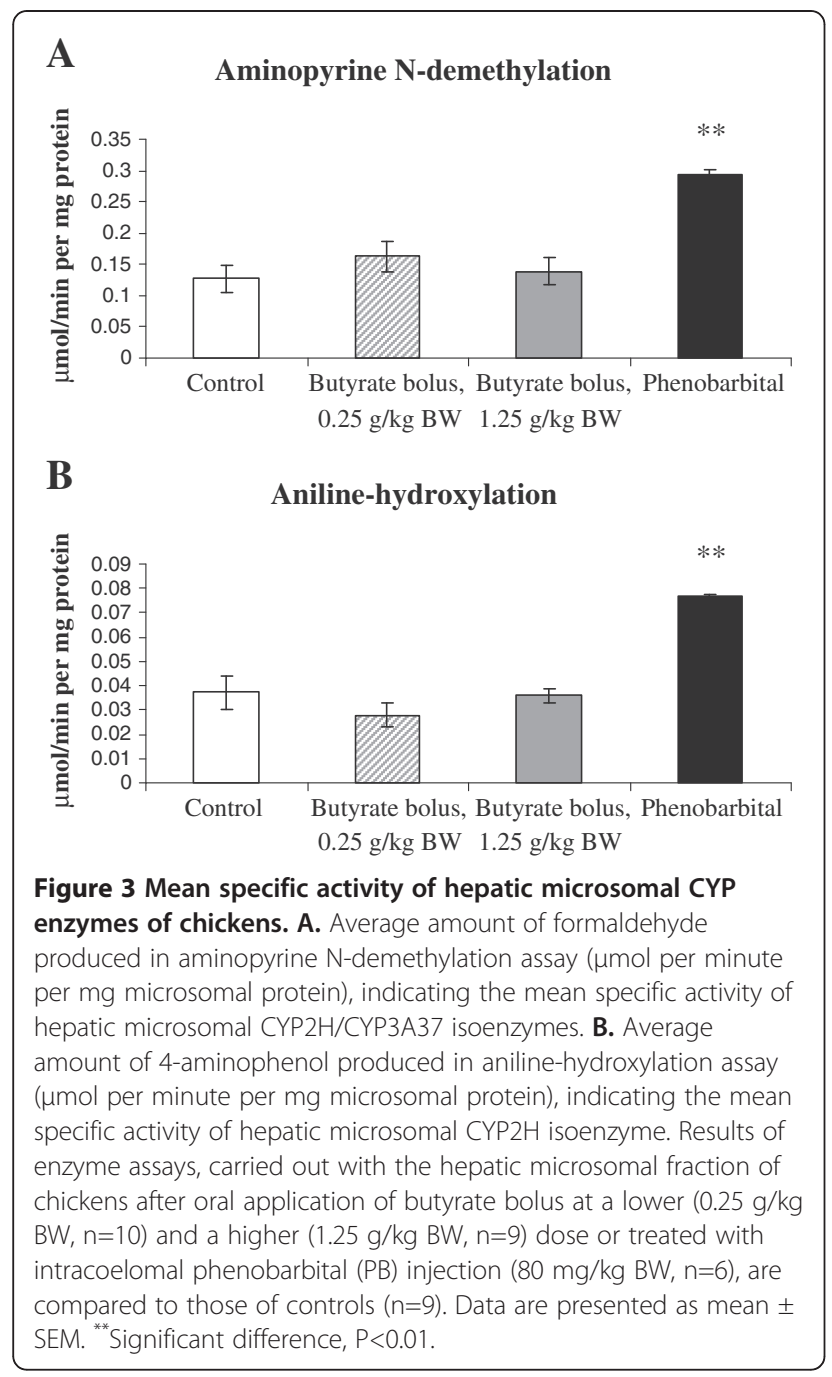

$\mathrm{K}_{\mathrm{M}}$ (lower dose: $\mathrm{P}=0.354$, higher dose: $\mathrm{P}=0.542$ ) values (Table 2) between control and butyrate-stimulated chickens, independently of the applied dose.

$\mathrm{PB}$ treatment enhanced significantly the CYP2H activity: increased mean reaction velocity $(\mathrm{P}=0.002)$ was measured (Figure $3 \mathrm{~B})$, but $\mathrm{V}_{\max }(\mathrm{P}=0.267)$ and $\mathrm{K}_{M}$ values were not affected $(\mathrm{P}=0.760)$ (Table 2 ).
These data are in agreement with our previous results [45], where we found that butyrate as a feed supplement did not alter the activity of hepatic CYP2H and CYP3A37 enzymes in chicken. Now, on the basis of our previous and recent results, it can be stated, that independently of the form of application and the applied dose, alimentary butyrate did not modify the activity of the examined CYP enzymes under physiological conditions.

However, butyrate's potential effects on other CYP subfamilies cannot be excluded. It is also not clear, whether under special dietary conditions or simultaneously applied with other agents, such as xenobiotics, butyrate may modify the liver enzymes of biotransformation. For example, dietary supplementation of inulin, a precursor of colonic butyrate production, in rats, suffering from high-fat-dietinduced hyperlipidaemia and hepatic steatosis, counteracted the decrease in the expression and activity of hepatic CYP1A1/2 and CYP2E1 enzymes [28].

\section{Conclusion}

The present study indicated that (1) orally applied butyrate in bolus had an impact on chromatin structure of hepatocytes in chicken in the early post-hatch period: independently of the dose, butyrate caused hyperacetylation of histone $\mathrm{H} 2 \mathrm{~A}$, but no changes were observed in the acetylation state of $\mathrm{H} 2 \mathrm{~B}$. The higher administered dose $(1.25 \mathrm{~g} / \mathrm{kg} \mathrm{BW})$ induced an intensive hyperacetylation of $\mathrm{H} 3$, while the application of the lower dose $(0.25 \mathrm{~g} / \mathrm{kg} \mathrm{BW})$ tended to increase acetylation ratio of H4. In addition, both treatments with butyrate bolus increased the expression of the H3.1 isoform. (2) These changes in the epigenetic regulation of cell function did not result in alteration of drug-metabolizing hepatic CYP2H and CYP3A37 enzyme activity, so there might be no relevant pharmacoepigenetic influences of orally applicated butyrate under physiological conditions.

Results of this and former studies indicate that growing chicken are a suitable model to evaluate the epigenetic effects of orally applied butyrate both by diet and by intra-crop application. Due to low endogenous butyrate

Table 2 Effects of oral application of butyrate on kinetic properties of cytochrome P450 (CYP) enzymes in chicken ${ }^{1}$

\begin{tabular}{|c|c|c|c|c|c|c|}
\hline Enzyme action & Responsible CYP & Kinetic parameter & Control & $\begin{array}{c}\text { Butyrate } 0.25 \mathrm{~g} / \mathrm{kg} \\
\mathrm{BW}^{2}\end{array}$ & $\begin{array}{c}\text { Butyrate } 1.25 \mathrm{~g} / \mathrm{kg} \\
\text { BW }^{2}\end{array}$ & $\mathrm{~PB}^{3}$ \\
\hline \multirow{2}{*}{$\begin{array}{l}\text { Aminopyrine } \\
\mathrm{N} \text {-demethylation }\end{array}$} & \multirow[t]{2}{*}{$\mathrm{CYP} 2 \mathrm{H} / 3 \mathrm{~A} 37$} & $V_{\max }(\mu \mathrm{mol} / \mathrm{mg} / \mathrm{min})$ & $0.22 \pm 0.06$ & $0.21 \pm 0.04$ & $0.17 \pm 0.03$ & $0.38 \pm 0.01^{* *}$ \\
\hline & & $K_{M}(m M)$ & $1.07 \pm 0.24$ & $1.20 \pm 0.33$ & $0.57 \pm 0.15$ & $1.02 \pm 0.14$ \\
\hline \multirow[t]{2}{*}{ Aniline-hydroxylation } & \multirow[t]{2}{*}{$\mathrm{CYP} 2 \mathrm{H}$} & $V_{\max }(\mu \mathrm{mol} / \mathrm{mg} / \mathrm{min})$ & $0.11 \pm 0.02$ & $0.15 \pm 0.04$ & $0.13 \pm 0.03$ & $0.19 \pm 0.01$ \\
\hline & & $\mathrm{K}_{\mathrm{M}}(\mathrm{mM})$ & $5.27 \pm 0.48$ & $12.25 \pm 4.36$ & $7.86 \pm 2.55$ & $3.27 \pm 0.45$ \\
\hline
\end{tabular}

${ }^{1}$ Values are shown as means \pm SEM (control: $n=9$; butyrate, lower dose: $n=10$; butyrate, higher dose: $n=9 ; P B: n=6$ ).

${ }^{2}$ Butyrate $=$ chickens treated with oral application of butyrate bolus in a lower $(0.25 \mathrm{~g} / \mathrm{kg} \mathrm{BW})$ and a higher $(1.25 \mathrm{~g} / \mathrm{kg} \mathrm{BW})$ dose.

${ }^{3} \mathrm{~PB}=$ chickens received intracoelomal phenobarbital injection $(80 \mathrm{mg} / \mathrm{kg} \mathrm{BW})$ on days $20-24$.

${ }^{* *}$ Significant difference, $\mathrm{P}<0.01$. 
production the histone acetylation is most likely derived from exogenous butyrate directly. Although this is a strictly descriptive study, this chicken model provides a high potential to identify butyrate-induced epigenetic mechanisms and their consequences in metabolic regulation in future.

\section{Abbreviations}

AME: Apparent metabolizable energy; ATP: Adenosine triphosphate; BSA: Bovine serum albumin; BW: Body weight; CYP: Cytochrome P450; EDTA: Ethylene diamino tetraacetic acid; HAT: Histone acetyltranferase; HDAC: Histone deacetylase; $\mathrm{K}_{\mathrm{M}}$ : Michaelis-Menten's constant; NADP $\mathrm{H}+\mathrm{H}^{+}$: Nicotinamide adenine dinucleotide phosphate (reduced form); PAGE: Polyacrilamide gelelectrophoresis; PB: Phenobarbital; PBST: Phosphate buffered saline supplemented with Tween; SCFA: Short chain fatty acids; SDS: Sodium dodecylsulphate; $V_{\text {max }}$ : Maximal reaction velocity.

\section{Competing interests}

The authors declare that they have no competing interests.

\section{Authors' contributions}

GM designed and carried out animal treatments and sampling, prepared the cell nucleus and microsomal fractions, conducted western blot examinations and enzyme assays and drafted the manuscript. ZsN conceived and designed the study, carried out sampling and revised the manuscript, GyCs designed the study, carried out sampling, analyzed data and revised the manuscript, AK carried out animal treatments and sampling, conducted enzyme assays and analyzed data. ÁK carried out sampling and prepared the cell nucleus and microsomal fractions, $\mathrm{KH}$ conducted the western blot examinations, analyzed data and revised the manuscript. All authors read and approved the final version of the manuscript.

\section{Acknowledgements}

Special thanks to Éva Fejes and Zsolt Wagner (Institute of Pharmacodynamics, Faculty of Pharmacology, Semmelweis University, Budapest, Hungary) for their help in the microsome isolation and to Kathrin Hansen (Department of Physiology, University of Veterinary Medicine, Hannover, Germany) for her help in the western blotting. The excellent assistance of our colleagues and students Janka Petrilla, Kata Annus, Tünde Benedek, Daniella Nyáry and Dániel Pleva (Department of Physiology and Biochemistry, Faculty of Veterinary Science, Szent István University, Budapest, Hungary) in the care for the animals and in the sampling is gratefully acknowledged. Thanks to Ferenc Mátis for his technical support in editing the figures.

\section{Author details}

'Department of Physiology and Biochemistry, Faculty of Veterinary Science, Szent István University, István utca 2, H-1078, Budapest, Hungary.

${ }^{2}$ Department of Pharmacology and Toxicology, Faculty of Veterinary Science, Szent István University, István utca 2, H-1078, Budapest, Hungary.

${ }^{3}$ Department of Physiology, University of Veterinary Medicine, Bischofsholer Damm 15/102, D-30173, Hannover, Germany.

Received: 3 October 2012 Accepted: 11 January 2013

Published: 22 January 2013

\section{References}

1. Bergman FN: Energy contributions of volatile fatty acids from the gastrointestinal tract in various species. Physiol Rev 1990, 70:567-590.

2. Roediger WE: Utilization of nutrients by isolated epithelial cells of the rat colon. Gastroenterology 1982, 83:424-429.

3. Gálfi $\mathrm{P}$, Neogrády S: The $\mathrm{pH}$-dependent inhibitory action of $\mathrm{n}$-butyrate on gastrointestinal epithelial cell division. Food Res Int 2002, 34:581-586.

4. Medina V, Edmonds B, Young GP, James R, Appleton S, Zalewski PD: Induction of caspase-3 protease activity and apoptosis by butyrate and trichostatin A (inhibitors of histone deacetylase): dependence on protein synthesis and synergy with a mitochondrial/cytochrome c-dependent pathway. Cancer Res 1997, 57:3697-3707.
5. Leu RKL, Hu Y, Brown IL, Young GP: Effect of high amylose maize starches on colonic fermentation and apoptotic response to DNA-damage in the colon of rats. Nutr Metab 2009, 6:11.

6. Young GP, Gibson PR (Eds): Butyrate and the human cancer cell. Cambridge: Cambridge University Press; 1995.

7. Mclntyre A, Gibson PR, Young GP: Butyrate production from dietary fibre and protection against large bowel cancer in a rat model. Gut 1993, 34:386-391.

8. Le Leu RK, Brown IL, Hu Y, Morita T, Esterman A, Young GP: Effect of dietary resistant starch and protein on colonic fermentation and intestinal tumourigenesis in rats. Carcinogenesis 2007, 28:240-245.

9. Ricke SC: Perspectives on the use of organic acids and short chain fatty acids as antimicrobiols. Poultry Sci 2003, 82:632-639.

10. Fernández-Rubio C, Ordónez C, Abad-González J, Garcia-Gallego A Pilar Honrubia M, Jose Mallo J, Balana-Fouce R: Butyric acid based feed additives help protect broiler chickens from Salmonella enteritidis infection. Poultry Sci 2008, 88:943-948.

11. Candela M, Maccaferri S, Turroni S, Carnevali P, Brigidi P: Functional intestinal microbiome, new frontiers in prebiotic design. Int J Food Microbiol 2010, 140:93-101.

12. Gálfi P, Bokori J: Feeding trial in pigs with a diet containing sodium n-butyrate. Acta Vet Hung 1990, 38:3-17.

13. Hu Z, Guo Y: Effects of dietary sodium butyrate supplementation on the intestinal morphological structure, absorptive function and gut flora in chickens. Anim Feed Sci Tech 2007, 132:240-249.

14. Phillips $I$ : Withdrawal of growth-promoting antibiotics in Europe and its effects in relation to human health. Int J Antimicrob Ag 2007, 30:101-107.

15. Biancotto C, Frigè G, Minucci S: Histone modification therapy of cancer. Adv Genet 2010, 70:341-386.

16. Davie JR: Inhibition of histone deacetylase activity by butyrate. J Nutr 2003, 133:2485S-2493S.

17. Candido EPM, Reeves R, Davie JR: Sodium butyrate inhibits histone deacetylation in cultured cells. Cell 1978, 14:105-113.

18. Kien CL, Peltier CP, Mandal S, Davie JR, Blauwiekel R: Effects of the in vivo supply of butyrate on histone acetylation of cecum in piglets. JPEN-Parenter Enter 2008, 32:51-56.

19. Guilloteau P, Martin L, Eeckhaut V, Ducatelle R, Zabielski R, Van Immerseel F: From gut to the peripheral tissues: the multiple effects of butyrate. Nutr Res 2010, 23:366-384.

20. Velázquez OC, Lederer HM, Rombeau JL: Butyrate and the colonocyte. Production, absorption, metabolism, and therapeutic implications. Adv Exp Med Biol 1997, 427:123-134.

21. Demigné C, Yacoub C, Rémésy C: Effects of absorption of large amounts of volatile fatty acids on rat liver metabolism. J Nutr 1986, 116:77-86.

22. Bloemen JG, Venema K, van de Poll MC, Olde Damink SW, Buurman WA, Dejong $\mathrm{CH}$ : Short chain fatty acids exchange across the gut and liver in humans measured at surgery. Clin Nutr 2009, 28:657-661.

23. Beauvieux MC, Tissier P, Gin H, Canioni P, Gallis JL: Butyrate impairs energy metabolism in isolated perfused liver of fed rats. J Nutr 2001, 131:1986-1992.

24. Gallis JL, Tissier P, Gin H, Beauvieux MC: Decrease in oxidative phosphorylation yield in presence of butyrate in perfused liver isolated from fed rats. BMC Physiol 2007, 7:8.

25. Gallis $J \mathrm{~L}, \mathrm{Gin} H$, Roumes $H$, Beauvieux MC: A metabolic link between mitochondrial ATP synthesis and liver glycogen metabolism: NMR study in rats re-fed with butyrate and/or glucose. Nutr Metab 2011, 8:38.

26. Baer-Dubowska W, Majchrzak-Celinska A, Cichocki M: Pharmacoepigenetics: a new approach to predicting individual drug responses and targeting new drugs. Pharmacol Rep 2011, 63:293-304.

27. Dannenberg LO, Edenberg HJ: Epigenetics of gene expression in human hepatoma cells: expression profiling the response to inhibition of DNA methylation and histone deacetylation. BMC Genomics 2006, 7:181.

28. Sugatani J, Sadamitsu S, Wada T, Yamazaki Y, Ikari A, Miwa M: Effects of dietary inulin, statin, and their co-treatment on hyperlipidemia, hepatic steatosis and changes in drug-metabolizing enzymes in rats fed a high-fat and high-sucrose diet. Nutr Metab 2012, 9:23.

29. Snel J, Harmsen HJM, Van der Wielen PWJJ, Williams BA: Dietary strategies to influence thegastrointestinal microflora of young animals and its potential to improve intestinal health. In Nutrition and Health of the Gastrointestinal Tract. Edited by Blok MC, Vahl HA, De Lange L, Van de Braak 
AE, Homko G, Hessing M. Wageningen: Wageningen Academic Publishers; 2000:37-60.

30. Ross Broiler Management Manual: 2009. http://www.poultryhub.org/wpcontent/uploads/2012/06/Ross_US_Broiler_Manual_09.pdf.

31. Van der Hoeven TA, Coon MJ: Preparation and properties of partially purified cytochrome $\mathrm{P}-450$ and reduced nicotinamide adenine dinucleotide phosphate-cytochrome P-450 reductase from rabbit liver microsomes. J Biol Chem 1974, 249:6302-6310.

32. Nash $\mathrm{T}$ : The colorimetric estimation of formaldehyde by means of the Hantzsch reaction. Biochem J 1953, 55:416-421.

33. García-Agúndez JA, Luengo A, Benítez J: Aminopyrine N-demethylase activity in human liver microsome. Clin Pharmacol Ther 1990, 48:490-495.

34. Murray M, Ryan AJ: Inhibition and enhancement of mixed-function oxidases by nitrogen heterocycles. Biochem Pharmacol 1982, 31:3002-3005.

35. Tobisawa Y, Imai Y, Fukuda M, Kawashima H: Sulfation of colonic mucins by $\mathrm{N}$-acetylglucosamine 6 -O-sulfotransferase-2 and its protective function in experimental colitis in mice. J Biol Chem 2010, 285:6750-6760.

36. Ishibasi T, Dryhurst D, Rose KL, Shabanowitz J, Hunt DF, Ausio J: Acetylation of vertebrate $\mathrm{H} 2 \mathrm{~A} . \mathrm{Z}$ and its effect on the structure of the nucleosome. Biochemistry-US 2009, 48:5007-5017.

37. Brower-Toland B, Wacker DA, Fulbright RM, Lis JT, Kraus WL, Wang MD: Specific contributions of histone tails and their acetylation to the mechanical stability of nucleosomes. J Mol Biol 2005, 346:135-146.

38. Zhang K, Williams KE, Hunag L, Yau P, Siino JS, Bradbury EM, Jones PR, Minch MJ, Burlingame AL: Histone acetylation and deacetylation. Mol Cell Proteomics 2002, 1:500-508.

39. Shin J, Li R, Gao Y, Baldwin R, Li C: Genome-wide ChIP-seq mapping and analysis reveal butyrate-induced acetylation of $\mathrm{H} 3 \mathrm{~K} 9$ and H3K27 correlated with transcription activity in bovine cells. Funct Integr Genomics 2012, 12:119-130.

40. Mathew OP, Ranganna K, Yatsu FM: Butyrate, an HDAC inhibitor, stimulates interplay between different posttranslational modifications of histone $\mathrm{H} 3$ and differently alters $\mathrm{G1}$-specific cell cycle proteins in vascular smooth muscle cells. Biomed Pharmacother 2010, 64:733-740.

41. Hake SB, Garcia BA, Duncan EM, Kauer M, Dellaire G, Shabanowitz J, Bazett-Jones $D P$, Allis CD, Hunt DF: Expression patterns and post-translational modifications associated with mammalian histone H3 variants. J Biol Chem 2006, 281:559-568.

42. Zhang K, Tang H, Huang L, Blankenship JW, Jones PR, Xiang F, Yau PM, Burlingame AL: Identification of acetylation and methylation sites of histone $\mathrm{H} 3$ from chicken erythrocytes by high-accuracy matrix-assisted laser desorption ionization-time-of-flight, matrix-assisted laser desorption ionization-postsource decay, and nanoelectrospray ionization tandem mass spectrometry. Anal Biochem 2002, 306:259-269.

43. Wu J, Zhou Z, Hu Y, Dong S: Butyrate-induced GPR41 activation inhibits histone acetylation and cell growth. J Genet Genomics 2012, 39:375-384.

44. Rada-lglesias A, Enroth S, Ameur A, Koch CM, Clelland GK, Respuela-Alonso P, Wilcox S, Dovey OM, Ellis PD, Langford CF, Dunham I, Komorowski J, Wadelius C: Butyrate mediates decrease of histone acetylation centered on transcription start sites and down-regulation of associated genes. Genome Res 2007, 17:708-719.

45. Mátis G, Neogrády Z, Csikó G, Gálfi P, Fébel H, Jemnitz K, Veres Z, Kulcsár A, Kenéz Á, Huber K: Epigenetic effects of dietary butyrate on hepatic histone acetylation and enzymes of biotransformation in chicken. Acta Vet Hung, . in press.

46. Li Y, Cui Y, Hart SN, Klassen CD, Zhong XB: Dynamic patterns of histone methylation are associated with oncogenic expression of the CYP3A4 genes during mouse liver maturation. Mol Pharmacol 2009, 75:1171-1179.

doi:10.1186/1743-7075-10-12

Cite this article as: Mátis et al:: Effects of orally applied butyrate bolus on histone acetylation and cytochrome P450 enzyme activity in the liver of chicken - a randomized controlled trial. Nutrition \& Metabolism 2013 10:12.

\section{Submit your next manuscript to BioMed Central and take full advantage of:}

- Convenient online submission

- Thorough peer review

- No space constraints or color figure charges

- Immediate publication on acceptance

- Inclusion in PubMed, CAS, Scopus and Google Scholar

- Research which is freely available for redistribution

Submit your manuscript at www.biomedcentral.com/submit
() Biomed Central 